\title{
MORPHOLOGICAL VARIATION OF ANTERIOR CLINOID PROCESS IN DRY HUMAN SKULLS
}

\author{
Dhakal $A^{1^{*}}$, Mehta $U^{2}$, Chaudhary $R^{2}$, Sah $S^{2}$
}

\begin{abstract}
Affiliation
1. Assistant Professor, Department of Anatomy, Birat Medical College and Teaching Hospital, Nepal

2. Lecturer, Department of Anatomy, Birat Medical College and Teaching Hospital, Nepal.
\end{abstract}

\section{ARTICLE INFO}

\section{Received : 12 July, 2019}

Accepted : 19 December, 2019

Published : 31 December, 2019

(C) Authors retain copyright and grant the journal right of first publication with the work simultaneously licensed under Creative Commons Attribution License CC - BY 4.0 that allows others to share the work with an acknowledgment of the work's authorship and initial publication in this journal.

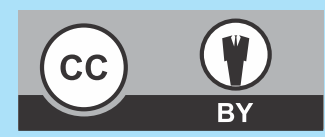

ORA 137

DOI: http://dx.doi.org/10.3126/bjhs.v4i3.27024

* Corresponding Author

Dr Arun Dhakal

Assistant Professor

Department of Anatomy

Birat Medical College and Teaching Hospital, Nepal

Email ID: arund@mail.ru

ORCID ID: https://orcid.org/0000-0002-2016-5713

\section{Citation}

Dhakal A, Mehta U, Chaudhary R, Sah S. Morphological Variation of Anterior Clinoid Process in Dry Human Skulls. BJHS 2019;4 (3)10: 813-817.

\section{ABSTRACT}

\section{Introduction}

The anatomical relationship of the Anterior Clinoid Process (ACP) with its neighboring structures in the base of the skull is complex with different variations. Thus, study of its morphology is essential in defining and directing surgery.

\section{Objective}

This study aims to investigate the anatomy of the anterior clinoid process and prevalence of Caroticoclinoid foramen (CCF) to highlight its variations.

\section{Methodology}

The measurements were performed in 31 dry human skulls to define the structure of ACP, the presence of CCF and other relevant landmarks using digital Vernier Calipers.

\section{Result}

The mean length, basal width and thickness of the right ACP was $9.88+/-1.36 \mathrm{~mm}, 8.72+/-1.50 \mathrm{~mm}$, and $5.21+/-1.83 \mathrm{~mm}$ respectively and that of the left was $10.30+/-1.47,8.73+/-$ 1.71 , and $5.33+/-1.60 \mathrm{~mm}$ respectively. Paired t-test was used to compare the mean of these sides. Type III was the most common form of ACP for both the sides. Out of 31 skulls, CCF was observed in 12 (38.7\%) skulls with 7 (22.6\%) in right and $5(16.13 \%)$ in left side. Distances between neighboring $A C P$ 's, between Posterior Clinoid process (PCP), between ACP to Crista Galli (CG) and ACP to PCP were $24.41+/-2.32,20.01+/-3.23,31.6+/-2.20$, and $8.30+/-3.10$ $\mathrm{mm}$ respectively.

\section{Conclusion}

The base width, length and thickness of ACP in our study have findings comparable to some white dissimilar to a few studies found in the literature. There was $38.7 \%$ unilaterally identify CCF without side differences and $0 \%$ Sella Turcica Biridge. The parasellar boundary was assessed in relation to the tip of ACP's position without significant difference between the sides.

\section{KEY WORDS}

Anterior clinoid process, caroticoclinoid foramen, nepalese, parasellar region 


\section{INTRODUCTION}

ACP is the medial end of the lesser wing of the sphenoid bone. ${ }^{1}$ Middle Clinoid Process (MCP) may be connected to the ACP by a thin osseous bar, formed by ossification of the caroticoclinoid ligament. The ensuing CCF surrounds the paraclinoidal segment of the internal carotid artery (ICA). ${ }^{2}$ This formation can hinder the exposure of ICA and cause damage to it. ${ }^{3}$ Topographically, ACP is related medially to the optic nerve, infero-medially to ICA and its ophthalmic branch, and infero-laterally to the oculomotor nerve.

Considering this complex relation of ACP in the base of the skull, the knowledge of its anatomy and topographical position is paramount, specially during anterior clinoidectomy which facilitates approach to enter the anterior cavernous sinus, expose aneurysms of the ICA, resect dural attachment, osseous ring of CCF and cavernous sinus meningiomas. ${ }^{4}$ It is also reported that clinoidectomy enhances mobilization of the intracranial ICA and optic nerve with less brain retraction. ${ }^{5}$ For safer surgical exposure the parasellar region is also critical in terms of lesions involving jugum sphenoidale, meningiomas, paraclinoidal aneurysms and tumors. Further more, one of the most common regions affected by many neoplastic and vascular neurosurgical lesions also falls in this area. $^{6}$

There are many articles devoted to assessing the dimensions of $A C P,{ }^{3,4,6-11}$ with limited study conducted in the Nepalese skulls. ${ }^{12}$ Therefore, our study aims to document the morphology and anatomical variation of ACP, assess parasellar landmarks in relation to ACP and evaluate the prevalence of CCF in Nepalese dry skulls.

\section{METHODOLOGY}

This study was carried out on 31 dry human skulls ( $n=62$ ACP) of unknown age and sex obtained from Department of anatomy of Birat Medical college and Maharajgunj Medical Campus from February to July of 2019. Damaged, diseased, and skulls having unilateral/bilateral clinoid and paraclinoid bony erosions were excluded (skulls with damaged unilateral clinoid processes were excluded so as to achieve consistency while measuring the distance between neighboring ACP's). Skulls with erupted third molars and without deformities and damage were included. All the measurements were done using digital Vernier Calipers of $0.1 \mathrm{~mm}$ caliber. Metrical parameters for ACP were defined as that of the study conducted by Lee et al. ${ }^{13}$ The width was measured at the base while the length was measured from the base to its tip (Figure 1 and 2). The presence of CCF was observed as a presence of a bony connection of ACP with the MCP (Figure 2). Classification of ACP is performed as described by Cecen et al. ${ }^{8}$ Classification of ACP is as follows: Type I [length $(<10.5 \mathrm{~mm})$, width $(>8.14 \mathrm{~mm})$ ], Type II [length $(>10.55 \mathrm{~mm})$, width $(<8.14$ $\mathrm{mm}$ )], Type III (length of $<10.5 \mathrm{~mm}$ and width of $<8.14 \mathrm{~mm}$ or length of $>10.5 \mathrm{~mm}$ and width of $>8.14 \mathrm{~mm}$ ).

Distances between the ACP and selected skull base structures were measured to estimate the clinoidal border of the parasellar region. This has implication in planning for a safe and effective approach to the parasellar region. Following distances were measured (Figure 1):

- $A=$ Height of ACP

- $B=$ Base of ACP

- $\quad \mathrm{C}=$ Between the posterior edge of the crista galli (CG) and the apex of the ACP

- $D=$ Between the apex of ACP and tip of the lateral-most projection of the PCP

- $E=$ Between the apexes of the ACP

- $F=$ Between the tips of the lateral-most extension of the PCPS

An Excel (Microsoft Corp.) spreadsheet was used for data entry with statistical analysis done using SPSS software (version 16.1, SPSS, Inc.). Means and standard deviations were obtained. Paired Student's ( $t$ ) test was used to calculate significant differences ( $p$ value $<0.05$ ).

\section{RESULT}

Metrical analysis (length, width, and thickness) was performed in the ACP of 31 skulls $(n=62)$. The mean length, basal width and thickness of the right ACP was $9.88+/-1.36 \mathrm{~mm}, 8.72+/-$ $1.50 \mathrm{~mm}$, and $5.21+/-1.83 \mathrm{~mm}$ respectively and that of the left was $10.30+/-1.47,8.73+/-1.71$, and $5.33+/-1.60 \mathrm{~mm}$ respectively (Table 1). Paired student's t-test was used to determine the significant difference. None of the parameters showed statistically significant differences between the right and the left sides. The most common type of ACP was type III [13 (41.9\%) right and $16(51.6 \%)$ left] followed by Type I [10 (32.3\%) right and 8(25.8\%)] and Type II [8 (25.8\%) right and 7(22.6\%) left] (Table 2).

Out of 31 skulls 12 (38.7\%) had unilateral CCF [7 (22.6\%) right and 5 (16.13\%) left]. None had bilaterally present CCF while $19(61.3 \%)$ skulls were devoid of it.

Measurements performed as detailed in the materials and methods section is illustrated in Table 3. Distances between neighboring ACP's, between Posterior Clinoid process (PCP), between ACP to Crista Galli (CG) and ACP to PCP were 24.41+/-2.32, 20.01+/-3.23, 31.6+/-2.20, and 8.30+/-3.10 mm respectively.

Table 1: Dimensions of Anterior Clinoid Process (mean
$+/-S D, m m$ )
\begin{tabular}{|l|c|l|l|}
\hline \multicolumn{1}{|c|}{ Parameter } & Right & \multicolumn{1}{|c|}{ Left } & P-value \\
\hline Length & $9.88+/-1.36$ & $10.30+/-1.47$ & 0.35 \\
\hline Width & $8.72+/-1.50$ & $8.73+/-1.71$ & 0.96 \\
\hline Thickness & $5.21+/-1.83$ & $5.33+/-1.60$ & 0.83 \\
\hline
\end{tabular}

P-value of $<0.05$ is considered significant

\begin{tabular}{|c|c|c|c|c|c|c|c|}
\hline \multirow[t]{2}{*}{ Side } & \multicolumn{2}{|c|}{ Width of ACP, $n(\%)$} & \multicolumn{2}{|c|}{ Length of ACP, $\mathbf{n}(\%)$} & \multirow{2}{*}{$\begin{array}{l}\text { Type I } \\
\text { n (\%) }\end{array}$} & \multirow{2}{*}{\begin{tabular}{|} 
Type II \\
n (\%)
\end{tabular}} & \multirow{2}{*}{$\begin{array}{c}\text { Type III } \\
\text { n (\%) }\end{array}$} \\
\hline & Narrow & Wide & Short & Long & & & \\
\hline Right & $13(41.9)$ & $18(58.1)$ & $20(64.5)$ & $11(35.5)$ & $10(32.3)$ & $8(25.8)$ & $13(41.9)$ \\
\hline Left & $10(32.3)$ & $21(67.7)$ & $14(45.1)$ & $17(54.5)$ & $8(25.8)$ & $7(22.6)$ & $16(51.6)$ \\
\hline
\end{tabular}

$\mathrm{n}=$ number of sample, Narrow $=<8.14 \mathrm{~mm}$, Wide $=>8.14 \mathrm{~mm}$, Short $=<10.5 \mathrm{~mm}$, Long $=>10.5 \mathrm{~mm}$ 


Table 3: Distances between the Anterior Clinoid Process
and related landmarks (mm)
\begin{tabular}{|l|l|c|c|c|c|}
\hline $\begin{array}{l}\text { S. } \\
\text { No }\end{array}$ & \multicolumn{1}{|c|}{ Distance } & $\begin{array}{c}\text { Right } \\
\text { (mean+/SD) }\end{array}$ & $\begin{array}{c}\text { Left } \\
\text { (mean+/-SD) }\end{array}$ & $\begin{array}{c}\text { Average } \\
\text { (mean+/ SD) }\end{array}$ & P-value \\
\hline 1 & $\begin{array}{l}\text { Between apex } \\
\text { of ACP and } \\
\text { posterior most } \\
\text { extension of } \\
\text { CG }\end{array}$ & $31.83+/-2.38$ & $31.32+/-2.24$ & $31.6+/-2.20$ & 0.07 \\
\hline 2 & $\begin{array}{l}\text { Between apex } \\
\text { of ACP and tip } \\
\text { of projection } \\
\text { of PCP }\end{array}$ & $8.17+/-3.49$ & $8.43+/-3.06$ & $8.30+/-3.10$ & 0.78 \\
\hline 3 & $\begin{array}{l}\text { Between apex } \\
\text { of ACP }\end{array}$ & - & - & $24.41+/-2.32$ & - \\
\hline 4 & $\begin{array}{l}\text { Between the } \\
\text { tip of PCP }\end{array}$ & - & - & $20.01+/-3.23$ & - \\
\hline
\end{tabular}

$\mathrm{CG}=$ Crista Galli, $\mathrm{PCP}=$ Posterior Clinoid Process, $\mathrm{P}$-value of $<0.05$ is considered significant

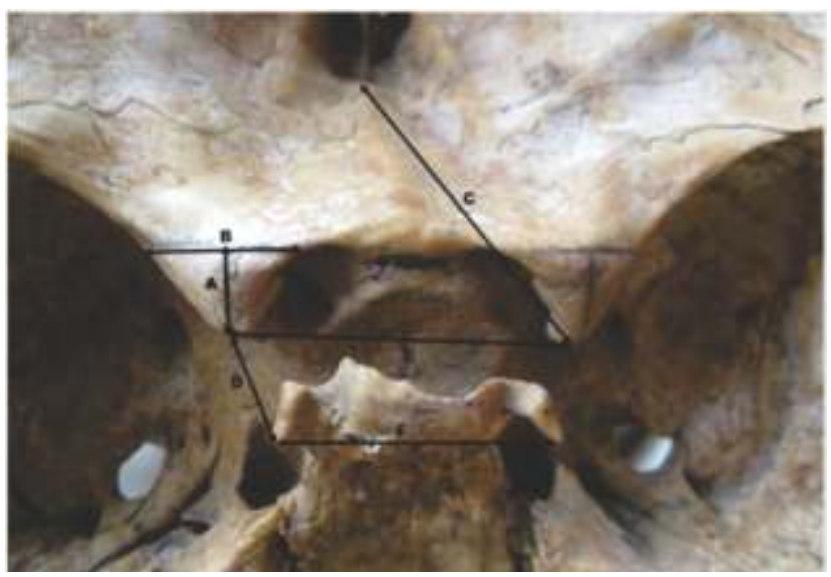

Figure 1: Photograph shows how the measurements were taken. (A) Height of ACP, (B) Base of ACP, (C) Distance between the posterior edge of the crista galli (CG) and the apex of the ACP, (D) Distance between the apex of ACP and tip of the lateral-most projection of the PCP, (E) Distance between the apexes of the ACP, (F) Distance between the tips of the lateral-most extension of the PCPs

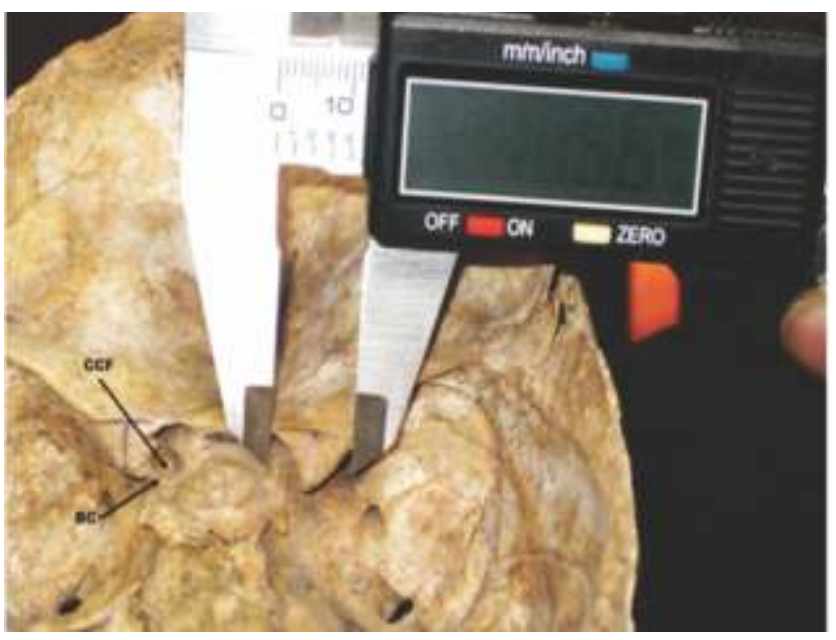

Figure 2: Photograph depicts the measurement of base of the right ACP. Arrow shows left CCF and BC (Bony connection between the tip of left ACP and MCP)

\section{DISCUSSION}

The sellar and the parasellar region have important anatomical relation with the pituitary gland and cavernous sinus with its content. Safe surgical resection of lesions involving the sellar, suprasellar and parasellar region via adequate surgical exposure is very crucial. Bony prominences in the region obscure visualization of vital neurovascular structures and can cause difficulty for safe exposure. ACP is the most significant prominences of the region as it directly overlies and obscures the optic nerve and ICA. ${ }^{6}$ Hence comprehending morphological feature of ACP and prevalence of CCF is crucial for a successful surgical outcome.

In our study of dry skulls, the base width, length, and thickness of ACP were comparable to various population studies, and at the same time different from others. ${ }^{3,6,7}$ It was larger than the study conducted by Kim et al. who found the average length and width to be $7.7 \mathrm{~mm}$ (range, 3-8 $\mathrm{mm}$ ) and $4 \mathrm{~mm}$ (range, 4-7 $\mathrm{mm}$ ) respectively and smaller than that of the study by Hunnargi et al. reporting length, basal width and thickness of ACP as $10.68+/-1.90 \mathrm{~mm}, 12.40+/-2.58 \mathrm{~mm}$ and $6.88+/-1.09 \mathrm{~mm}$ respectively., ${ }^{4,11}$ There was no significant symmetry disagreement between the ACP dimensions of the right and left side in the present study unlike that reported by Lee et al. where all the measured parameters between both the sides were significantly different. ${ }^{13}$ In contrast to this, the study by Souza et al. only had the width of ACP significantly different between the right and left sides. ${ }^{9}$ The observed difference in the sizes of ACP could be due to factors attributable to methodology, age, gender, racial or genetic factors.

Anterior clinoidectomy creates a space that does not exist with clinoid process in place. This space is a potential space enclosed by outer dural layer superiorly and inner dural layer inferiorly. This surgically created interdural, extra cavernous space is referred to as the clinoid space. ${ }^{14}$ Surgical techniques implied in anterior clinoidectomies are influenced by the length and width of ACP. ${ }^{8}$ Based on the dimensions of the ACP, Cecen et al. described the types of ACP which possibly may help surgeons predict space achievable after anterior clinoidectomies. Majority of the ACP in our study belonged to type III, a comparison similar to the result of Cecen et al.

The MCP is a bony projection that arises from the lateral surface of the body of the sphenoid bone below the tuberculum sellae. A complete bony fusion between the ACP and MCP can exist forming a CCF. An inter clinoid bony connection can form between the ACP and the PCP, also referred to as the STB (Sella Turcica Bridge). ${ }^{7}$ Observation by Keyes in a large sample study classified CCF which most of the studies followed to define their findings. ${ }^{3,4,6,9,12,15}$ Overall, we found $38.7 \%$ CCF without side differences and 0\% STB in 31 skulls. Lee et al. found CCF and STB in $15.7 \%$ and $5.5 \%$ of 73 skulls respectively. ${ }^{3}$ Kim et al. found CCF and STB in $37 \%$ and $5.5 \%$ of 35 formalin fixed cadavers respectively. ${ }^{4}$ Dagtekin et al. found CCF and STB in $25 \%$ and $5 \%$ of 15 formalin fixed 
cadaver heads and 25 dry skulls respectively. ${ }^{6}$ Costa et al. found CCF and STB in $14.2 \%$ and $14.4 \%$ of 597 skull respectively. ${ }^{7}$ It follows that the prevalence of STB and CCF ranges from $5 \%$ to $15 \%$ and $14 \%$ to $38 \%$ respectively. ${ }^{3,4,6,7}$ Keyes in his work found bilateral CCF in $23.41 \%$ and unilateral in $8.68 \%$ and STB in $8.68 \%$ of 2187 skulls. ${ }^{15}$ This finding is in contrast to our study with CCF only present unilaterally in $38.7 \%$ and absent STB which in turn is contrary to the work of Gupta et al. reporting CCF and STB in $20 \%$ and $2.85 \%$ of 35 skulls respectively. ${ }^{12}$ Regardless of our study conducted in similar population as that of Gupta et al., the length and basal width of ACP did not match, while the thickness was comparable. This inconsistency could be due to selection criteria or small sample size of both the studies. Excluding skulls with unilateral bony erosion/ damage in our study may be another reason of differing findings in STB. Knowledge of CCF and STB have clinical significance in assisting surgeons to adjust their approach to sella turcica or skull base regions preoperatively and avoiding injury to ICA, cavernous sinus or the optic nerve.

The ACP and PCP are the most prominent bony processes of the parasellar region. These are present in the superolateral aspect of the tuberculum sellae and the dorsum sellae respectively contributing to the boundary of the sella turcica. Furthermore, these also occupy a unique position in the centre of the skull base giving it a useful foundation in constructing a sectional map of the skull base. Dimensions and variations in the $A C P$ and $P C P$ together with the $M C P$, STB and CCF are crucial structures affecting the size and utility of the map. Table 3 and Figure 1 illustrate various measurements taken to quantify the dimension of the parasellar region limited by CG anteriorly, ACP anterolaterally and PCP posterior and posteriolaterally. The distances we measured gives a general idea of the extension of commonly used skull based approach in transnasal and transsphenoidal approach. ${ }^{16,17}$ The distances between neighboring ACP's and PCP's, between ACP to CG and ACP to PCP were $24.41+/-2.32$, $20.01+/-3.23,31.6+/-2.20$, and $8.30+/-3.10 \mathrm{~mm}$ respectively. Also, the differences between the sides were considered which were statistically insignificant. Comprehensive anatomy of the ACP and its relation to other skull base landmarks could enhance surgical point of reference in guiding proper approach to the skull base.

\section{CONCLUSION}

The base width, length, and thickness of ACP in our study have findings comparable to some while dissimilar to a few studies found in the literature. Majority of the ACP were of type III variation with no significant symmetry disagreement between the right and the left side. There was $38.7 \%$ unilaterally identified CCF without side differences and $0 \%$ STB. The distances between neighboring $A C P$ and $P C P$, between ACP to CG and ACP to PCP were assessed to discern the parasellar boundary in relation to the tip of ACP's position. Statistically there was no significant difference between the sides.

\section{RECOMMENDATION}

This study recommends an increase in sample size and conduct radiological (CT based) study together with dry specimens for future work in the field.

\section{LIMITATION OF THE STUDY}

The sample size of the study is small and hypothesis may not be generalized.

\section{ACKNOWLEDGEMENT}

We would like to express our sincere gratitude to Prof. Dr. Nirju Ranjit, HOD of Department of Anatomy of Maharajgunj Medical Campus for providing access to the department's museum to conduct this study. We would also like to acknowledge the members of IRC (Institutional Review Committee) and faculty of anatomy department of Birat Medical College and Maharajgunj Medical Campus for their support and cooperation throughout this study.

\section{CONFLICT OF INTEREST}

None to declare.

\section{REFERENCES}

1. Standring, S., 2016. Gray's Anatomy: the anatomical basis of clinical practice. 41st edition, Edinburgh: Churchill Livingstone, 430-431.

2. Fernandez-Miranda JC, Tormenti M, Latorre F, Gardner P, Snyderman C. Endoscopic endonasal middle clinoidectomy: anatomic, radiological, and technical note. Neurosurgery. 2012;71(2 Suppl Operative):ons233-239; discussion ons239. doi:10.1227/ NEU.0b013e3182690b6b

3. Lee HY, Chung IH, Choi BY, Lee KS. Anterior clinoid process and optic strut in Koreans. Yonsei Med J. 1997;38(3):151-154. doi:10.3349/ ymj.1997.38.3.151

4. Kim JM, Romano A, Sanan A, van Loveren HR, Keller JT. Microsurgical anatomic features and nomenclature of the paraclinoid region. Neurosurgery. 2000;46(3):670-680; discussion 680-672. doi:10.1097/00006123-200003000-00029
5. Matsuyama T, Shimomura T, Okumura Y, Sakaki T. Mobilization of the internal carotid artery for basilar artery aneurysm surgery. Technical note. J Neurosurg. 1997;86(2):294-296. doi:10.3171/ jns.1997. 86.2.0294

6. Dagtekin, E. Avci, D. Uzmansel, Z. Kurtoglu, E. Kara, K. Uluc, et al. Microsurgical anatomy and variations of the anterior clinoid process. Turk Neurosurg. 2014;24(4): 484-493. DOI: 10.5137/10195149.JTN.8738-13.1

7. da Costa MDS, de Oliveira Santos BF, de Araujo Paz D, et al. Anatomical Variations of the Anterior Clinoid Process: A Study of 597 Skull Base Computerized Tomography Scans. Oper Neurosurg (Hagerstown). 2016;12(3):289-297. doi:10.1227/neu. 0000000000001138 
8. Cecen A, Celikoglu E, Is M, Kale A, Eroglu B. Pre-Operative Measurement of the Morphometry and Angles of the Anterior Clinoid Process (ACP) for Aneurysm Surgery. International Journal of Morphology. 2016;34:1333-1338. doi:10.4067/S071795022016000400026

9. Souza AD, Ankolekar VH, Nayak N, Hosapatna M, Souza AS. Morphometric Study of Anterior Clinoid Process and Optic Strut and the Ossification of Carotico-Clinoid Ligament with their Clinical Importance. J Clin Diagn Res. 2016;10(4):Ac05-07. doi:10.7860/ jcdr/2016/19316.7520

10. Lehmberg J, Krieg SM, Meyer B. Anterior clinoidectomy. Acta Neurochirurgica. 2014;156(2):415-419. DOI 10.1007/s00701013-1960-1

11. Hunnargi S, Ray B, Pai SR, Siddaraju KS. Metrical and non-metrical study of anterior clinoid process in South Indian adult skulls. Surg Radiol Anat. 2008;30(5):423-428. doi:10.1007/s00276008-0346-1

12. Gupta N, Ray B, Ghosh S. A study on anterior clinoid process and optic strut with emphasis on variations of caroticoclinoid foramen. Nepal Med Coll J. 2005;7(2):141-144. PMID:16519084
13. Lee HW, Park HS, Yoo KS, Kim KU, Song YJ. Measurement of Critical Structures around Paraclinoidal Area : A Cadaveric Morphometric Study. J Korean Neurosurg Soc. 2013;54(1):14-18. doi:10.3340/jkns.2013.54.1.14

14. Sekhar LN, Burgess J, Akin O. Anatomical study of the cavernous sinus emphasizing operative approaches and related vascular and neural reconstruction. Neurosurgery. 1987;21(6):806-816. doi:10.1227/ 00006123-198712000-00005

15. Keyes JEL. Observations on four thousand optic foramina in human skulls of known origin. Arch Ophthalmology. 1935;13:538-68. doi:10.1001/archopht.1935.00840040026002

16. Kassam A, Snyderman CH, Mintz A, Gardner P, Carrau RL. Expanded endonasal approach: the rostrocaudal axis. Part I. Crista galli to the sella turcica. Neurosurg Focus. 2005;19(1):E3. https://doi.org/ 10.3171/foc.2005.19.1.4

17. Wang Q, Lan Q, Lu XJ. Extended endoscopic endonasal transsphenoidal approach to the suprasellar region: anatomic study and clinical considerations. J Clin Neurosci. 2010;17(3):342-346. doi:10.1016/j.jocn.2009.05.032. 